\title{
Correction to: Outcomes After Laparoscopic Conversion of Failed Adjustable Gastric Banding (LAGB) to Laparoscopic Sleeve Gastrectomy (LSG) or Single Anastomosis Duodenal Switch (SADS)
}

\author{
Sarah Pearlstein $^{1} \cdot$ Sarah A. Sabrudin $^{1} \cdot$ Ali Shayesteh $^{1}$ (D) Eric R. Tecce ${ }^{1} \cdot$ Mitchell Roslin $^{1}$
}

Published online: 7 March 2019

(C) Springer Science+Business Media, LLC, part of Springer Nature 2019

\section{Correction to: Obesity Surgery}

https://doi.org/10.1007/s11695-019-03729-3

In the original article the Conflict of Interest statement was incomplete. Dr. Roslin discloses that he is a teaching consultant for Ethicon and Medtronics. He also has received research funding from Medtronics.

Publisher's Note Springer Nature remains neutral with regard to jurisdictional claims in published maps and institutional affiliations.

The online version of the original article can be found at https://doi.org/ 10.1007/s11695-019-03729-3

\footnotetext{
Ali Shayesteh

a.shayesteh3@gmail.com

1 Department of General Surgery, Zucker School of Medicine at Hofstra/Northwell at Lenox Hill Hospital Program, New York, NY 10021, USA
} 